\title{
AS CONTRIBUIÇÕES DA MEMÓRIA NA FORMAÇÃO CONTINUADA DE PROFESSORES
}

\author{
Jane do Carmo Machado \\ Universidade Federal Fluminense w Universidade Católica de Petrópolis \\ E-mail: jane.machado@ucp.br
}

THE CONTRIBUTIONS OF THE MEMORY IN THE TEACHERS CONTINUOUS TRAINING

\section{Rui Neves}

Universidade de Aveiro

E-mail: rneves@ua.pt

\section{Resumo}

Este artigo centra-se na análise do potencial da memória de trabalho e de formação de professores retomada nos Ateliês de formação continuada e em serviço de professores desenvolvidos na própria escola a partir dos sentidos por esses sujeitos atribuídos. Adotouse uma investigação de natureza qualitativa, baseada nos pressupostos teóricos da análise de conteúdo. Os dados foram recolhidos (2013) a partir de entrevistas semiestruturadas com professores e orientadoras pedagógicas da rede de ensino municipal de Petrópolis, RJ Brasil. Os resultados levam a inferir que os sujeitos consideram que tal memória contribui com a sua reflexão sobre o seu trabalho docente de modo a encontrarem um caminho para enriquecer o processo de ensino-aprendizagem.

Palavras-chave: formação continuada de professores. prática docente. memória.

\begin{abstract}
The article focuses on the analysis of the potential of the teachers' work and formation memory bringing back in the continuous training workshops which are developed at the school from the meanings attributed for them. A qualitative research based on theoretical assumptions of content analysis was adopted. The data were collected (2013) from the semistructured interviews with teachers and pedagogic counselors who work in schools of the Petrópolis municipal teaching network, RJ - Brazil. The results lead to the inference that teachers and pedagogic counselors consider that their memory of work and formation contributes with their reflection about their teaching work in order to improve the teachinglearning process.
\end{abstract}

Palavras-chave: teachers continuous training. teaching practice. memory. 


\section{INTRODUÇÃO}

As contribuições da memória de formação e trabalho de professores e orientadoras pedagógicas surgem como principal conteúdo de análise dos sentidos por esses sujeitos atribuídos a essa memória durante os Ateliês de formação continuada e em serviço de professores realizados na própria escola. Para Machado (2011; 2015), os Ateliês são espaços privilegiados de formação continuada e em serviço onde os professores, tanto individual como coletivamente, têm a oportunidade de partilharem o que já viveram, trazendo para o centro das discussões suas experiências, seus saberes, seus conhecimentos, suas aprendizagens e não-aprendizagens, buscando tornar o vivido parte de seu repertório, assumido-o como patrimônio capaz de ressignificar o passado e apontar caminhos no futuro. Nessa perspectiva, esse repertório de memórias de trabalho e de formação partilhado pode, dependendo do modo como acontece essa rememoração e dos sentidos atribuídos pelos sujeitos participantes, ser traduzido e concebido a partir de uma perspectiva de aprendizagem durante o processo de socialização-reflexão levado a cabo nesses ateliês de formação.

Assim, parte-se do pressuposto que a memória pode mobilizar e colocar os professores em um movimento retrospectivo em que a rememoração pode ser potencializadora também de uma visão prospectiva sobre a sua atividade docente e também sobre o seu processo de formação continuada. Entretanto, o fato de essa memória docente poder tornar-se repertório transformado em patrimônio de trabalho e formação não garante que será preservada e usada como dispositivo para outras aprendizagens, uma vez que a forma de preservação e o uso dado estão intimamente relacionados aos sentidos a ela atribuídos por cada um dos envolvidos a partir das suas próprias experiências.

Diante do exposto, considera-se relevante trazer para o centro das discussões aqui apresentadas algumas alocuções de professores e orientadoras pedagógicas que apontam, durante os ateliês de formação, a memória sendo assumida na perspectiva de memória exemplar de Todorov (2011a; 2011b). Nesse sentido, atribui-se a memória importante papel, 
especialmente para tornar as experiências vividas por esses professores mais potencializadoras de outras que estarão por viver.

\section{PERCURSO METODOLÓGICO}

Este estudo, de natureza qualitativa, centrou-se na análise do potencial atribuído à memória de trabalho e de formação de professores e orientadoras pedagógicas que participaram da pesquisa intitulada "Ateliê de formação e em serviço de professores: desafios e possibilidades"1 $^{1}$, considerando suas próprias alocuções. Os dados são decorrentes de 19 entrevistas semiestruturadas realizadas no primeiro semestre de 2013 com esses sujeitos sobre a sua participação nos ateliês de formação ${ }^{2}$ desenvolvidos em escolas do Ensino Fundamental, Educação Básica, da rede municipal de ensino de Petrópolis, RJ-Brasil.

O tratamento dos dados ancora-se na análise de conteúdo (BARDIN, 2013) em uma perspetiva interpretativa das alocuções desses professores. Para a organização, agrupamento e codificação dos dados, utilizou-se o apoio do software WebQDA - versão 2.0.0 - (COSTA; LINHARES; NERI DE SOUZA, 2012), cujo formato viabiliza a construção de categorias a partir de nós principais e subnós e permite um trânsito mais dinâmico do pesquisador sobre os dados.

Assim, frente aos dados recolhidos durante a pesquisa de campo, a pesquisadora precisou assumir uma posição crítica e comprometida para poder tomar decisões que viabilizassem a análise desses dados de modo a que correspondessem aos sentidos a eles atribuídos pelos sujeitos . Como postulado por Bogdan e Biklen (2010), o pesquisador, diante dos dados recolhidos, acaba por se imaginar em um grande ginásio com milhares de brinquedos espalhados pelo chão os quais demandam uma decisão que possa viabilizar uma melhor

1 Esta pesquisa está vinculada a Tese de Doutorado defendida em 24 de fevereiro de 2015 no Programa de Pós-graduação em Educação da Universidade Federal Fluminense - RJ.

2 Ateliês de formação e em serviço de professores considerados espaços voltados para o desenvolvimento de práticas formativas na escola, em que os professores têm a oportunidade de refletir criticamente sobre o próprio trabalho de modo a potencializá-lo (MACHADO, 2011; 2015). 
organização, interpretação e análise dos mesmos.

Como orientadora pedagógica dessa mesma rede de ensino, a pesquisadora precisou também aproximar-se da perspectiva de Velho (2012) quando sustenta que um tempo razoavelmente longo de contato com os sujeitos pesquisados pode possibilitar o conhecimento dos pontos de vista e das visões de mundo dos diferentes sujeitos em situações sociais que estão sendo observadas, mesmo que essas possam parecer familiares aos olhos do pesquisador, elas podem sempre suscitar situações de estranheza, dependendo da posição que o pesquisador se coloca, assumindo o objeto de estudo a partir de uma reflexão sistemática. Desse modo,

Posso estar acostumado...com uma certa paisagem social onde a disposição dos atores me é familiar, a hierarquia e a distribuição de poder permitemme fixar, grosso modo, os indivíduos em categorias mais amplas. No entanto, isto não significa que eu compreenda a lógica de suas relações. 0 meu conhecimento pode estar seriamente comprometido pela rotina, hábitos, esteriótipos. Logo, posso ter um mapa mas não compreendo necessariamente os princípios e mecanismos que o organizam (VELHO, 2012, p.7).

Nesse sentido, para o autor, tanto o familiar quanto o exótico no processo de investigação e análise podem suscitar e envolver diferentes dificuldades que, ao longo, devem ser minimizadas ao recorrer aos conhecimentos disponíveis sobre o fato e os sujeitos em questão. Ao fazer referência a Da Matta, o autor lembra da dificuldade de o pesquisador "transformar o exótico em familiar e o familiar em exótico" como um grande desafio a ser superado. Estranhar o familiar vai exigir, apesar da subjetividade envolvida, capacidade de afastamento crítico, sistematizado: "O processo de estranhar o familiar torna-se possível quando somos capazes de confrontar intelectualmente, e mesmo emocionalmente, diferentes versões e interpretações existentes a respeito de fatos, situações" (VELHO, 2012, p. 12). 


\subsection{Aportes teóricos}

A formação de professores, especialmente a formação continuada, segundo autores como Alarcão (1998; 2001; 2010a), Freire (2005), Tardif (2005), Formosinho (2009), Nóvoa (2009), Imbernón (2009; 2010; 2011), Benachio e Placco (2012) precisa estabelecer uma relação com o próprio trabalho pelo professor desenvolvido para que possa potencializar esse trabalho a partir do que é passível de ressignificação e aprendizagem. Pensar o processo de formação relacionado ao trabalho vai demandar não só a retomada das experiências já vividas, mas também uma reflexão-ação prospectiva desse trabalho. Quando os professores participam de propostas de formação que os colocam em contato direto com situações por eles ou pelos pares vividas têm a possibilidade de, ao revisitá-las, atribuir-Ihes um outro sentido a partir das articulações que conseguir fazer com suas experiências, saberes e conhecimentos. Nessa linha, Nóvoa (2009) sustenta que a formação de professores ganharia muito se fosse organizada em torno de situações concretas, de insucesso escolar, de problemas escolares ou de programas de ação educativa em que os professores pudessem mobilizar seus conhecimentos teóricos para poder resolver tais situações de modo a responder às demandas próprias da atividade docente. Nessa retomada do passado, das situações concretas vividas, a memória surge como grande aliada, pois viabiliza uma reaproximação do vivido de forma a torná-lo mais significativo, especialmente quando essa memória é retomada na perspectiva exemplar.

Assim, a memória exemplar (TODOROV, 2011a; 2011b) seria a que concebe os acontecimentos passados de modo mais generalizado, sem deixar que percam sua singularidade e sejam percebidos mais amplamente, podendo promover um ensinamento sobre o presente. O dever de memória implica pensar tanto nos bons usos, como nos abusos que se faz desse resgate do passado. Desse modo, o culto à memória encontra-se, na perspectiva do autor, presente especialmente na sociedade ocidental, em regimes totalitaristas que defendiam um processo de apropriação e de controle da memória, relacionado a situações consideradas traumáticas, carregadas de dor, de violência, de 
abandono, de poder, que deixavam nos sujeitos marcas fortes e profundas, embora pudessem também beneficiar os que a evocavam ou evocam hoje. Se o processo de rememoração estava muito ligado a um processo de sofrimento, não poderiam esses sujeitos a partir do vivido buscar outros sentidos que potencializem sua reflexão e libertação a fim de que optassem por fazer bom uso dessa memória, rejeitando os abusos?

Assim, se, nos ateliês, os professores e orientadoras pedagógicas optarem por fazer um bom uso da memória, principalmente da memória de trabalho articulada à memória de formação, vão precisar se colocar ativamente diante de suas necessidades e expectativas relacionadas à própria atividade docente.

Ao se considerar o bom uso da memória, pode-se eleger como caminho de retomada do passado, que algumas vezes ocorre de forma voluntária e outras involuntária, um processo que exija do sujeito um envolvimento mais direto sobre seu processo de rememoração a fim de que se revele significativo para o presente e o futuro.

Por conseguinte, quando os professores e orientadoras pedagógicas têm a oportunidade de durante a sua formação continuada buscarem as contribuições da memória para a compreensão das experiências vividas com vistas a transformá-las em pistas que fazem uma ponte entre o passado, o presente e o futuro não segundo uma perspectiva de nostalgia ou sofrimento sobre esse passado, mas sim como um dispositivo emancipador que pela aprendizagem faz rever, avaliar e ressignificar o vivido e o a viver.

A formação de professores, especialmente a formação continuada, segundo autores como Nóvoa (2009), Alarcão (1998; 2001; 2010a), Freire (2005), Formosinho (2009) precisa estabelecer uma relação com o próprio trabalho pelo professor desenvolvido para que possa potencializar esse trabalho a partir do que é passível de ressignificação e aprendizagem. Pensar o processo de formação relacionado ao trabalho vai demandar não só a retomada das experiências já vividas, mas também uma reflexão-ação prospectiva desse trabalho. 
A memória exemplar (TODOROV, 2011a; 2011b) seria a que concebe os acontecimentos passados de modo mais generalizado, sem deixar que percam sua singularidade e sejam percebidos mais amplamente, podendo promover um ensinamento sobre o presente. Assim, o dever de memória implica pensar tanto nos bons usos, como nos abusos que se faz desse resgate do passado. Desse modo, o culto à memória encontra-se, na perspectiva do autor, presente especialmente na sociedade ocidental, em regimes totalitaristas que defendiam um processo de apropriação e de controle da memória, relacionado a situações consideradas traumáticas, carregadas de dor, de violência, de abandono, de poder, que deixavam nos sujeitos marcas fortes e profundas, embora pudessem também beneficiar os que a evocavam ou evocam hoje. Se o processo de rememoração estava muito ligado a um processo de sofrimento, não poderiam esses sujeitos a partir do vivido buscar outros sentidos que potencializem sua reflexão e libertação a fim de que optassem por fazer bom uso dessa memória, rejeitando os abusos? Assim, se, nos ateliês, os professores e orientadoras pedagógicas optarem por fazer um bom uso da memória, principalmente da memória de trabalho articulada à memória de formação, vão precisar se colocar ativamente diante de suas necessidades e expectativas relacionadas à própria atividade docente.

Ao se considerar o bom uso da memória, pode-se eleger como caminho de retomada do passado, que algumas vezes ocorre de forma voluntária e outras involuntária, um processo que exija do sujeito um envolvimento mais direto sobre seu processo de rememoração a fim de que se revele significativo para o presente e o futuro.

Por conseguinte, quando os professores e orientadoras pedagógicas têm a oportunidade de durante a sua formação continuada buscarem as contribuições da memória para a compreensão das experiências vividas, narrando-as e sendo narrado por elas (BENJAMIN, 1996), com vistas a transformá-las em pistas que fazem uma ponte entre o passado, o presente e o futuro não segundo uma perspectiva de nostalgia ou sofrimento sobre esse passado, mas sim como um dispositivo emancipador que pela aprendizagem faz rever, avaliar 
e ressignificar o vivido e o a viver.

\section{DOS RESULTADOS: O POTENCIAL DA MEMÓRIA EXEMPLAR}

Neste estudo, considerando a extensão da pesquisa a ele relacionada, foram selecionadas algumas alocuções e os sentidos pelos participantes atribuídos que têm como base a memória desses sujeitos sobre seus próprios processos de formação e de trabalho.

Diante dos dados, assumindo a perspectiva referendada por Velho (2009) sobre a possibilidade de se estranhar o familiar, buscou-se um mergulho nos dados que oportunizasse um aproximar e um afastar das perspectivas apontadas pelos sujeitos sobre o potencial da memória para ressignificar o próprio trabalho e a formação continuada.

Importa trazer algumas alocuções que sustentam a importância da memória em um processo de ressignificação do vivido e do a viver. Nesse sentido, quando Freire (2005) aponta que a atividade docente exige dos professores, como sujeitos inconclusos, um pensar criticamente a prática de hoje e de ontem para poderem melhorar a próxima prática, estando, portanto, em processo permanente de formação, o resgate da memória desses professores torna-se essencial para que possam rever e ressignificar seus próprios processos de formação e de trabalho. Assim, nas alocuções seguintes é possível perceber essas idas e vindas que os professores fazem de seus percursos quando revividos por meio desse mergulho feito em suas próprias memórias.

Sim, é o momento em que você tem pra refletir né, quando você coloca, quando o outro se coloca você consegue, começa comparando: "Espera aí, que é que eu faço né?", "O que é que eu tô acertando?", "O que é que eu tô errando?", a gente, eu consigo, assim, ver as minhas falhas e acertos na hora, no momento da conversa, na leitura de um texto, na hora que o colega se coloca né, como ele faz aquilo, eu falo: "Nossa.". É você, é um momento pra você se criticar e se colocar, 
refletir mesmo: "Eu faço isso, mas isso não é bacana" ou então "Eu faço isso e isso é legal.", "Aquilo que ele faz é legal.". Vejo assim um momento muito importante de avaliações nesses encontros né (Professora Adélia - Entrevista).

Eu acho que a gente sente falta de tá ali conversando com o colega, de tá trocando com ele, não os colegas só da nossa área, mas das outras áreas também. Eu lembro que eu já aproveitei muitas dicas que colegas professores de outras áreas me deram (Professora Paula - Entrevista).

Essas alocuções podem apontar as muitas possibilidades abertas para se olhar o próprio trabalho e o dos pares a partir de outro ângulo de visão capaz de ampliar e aprofundar a reflexão sobre sua atividade docente. Daí se defender a necessidade de criação de espaços para que os professores no coletivo retomem suas experiências de trabalho por meio da memória exemplar e, tal como postulado por Sarmento (2009), possam aproveitar o contato com os colegas como produtor de aprendizagem pelo erro que se observa. De fato, quando a professora Adélia, na sua reflexão individual diz: "Espera aí, que é que eu faço né?", "'O que é que eu tô acertando?", "O que é que eu tô errando?", está fazendo um retorno ao seu próprio passado vivido usando a prática do outro professor como um espelho que reflete a sua e, ao mesmo tempo, abre outros caminhos, indica outras opções que podem contribuir para a melhoria de seus próprios processos.

A mesma autora defende que a voz dos professores surge como fundamento de conhecimento das suas experiências formativas. Nessa linha, argumenta-se que a memória exemplar tornada visível e concreta por meio da voz dos professores pode promover uma releitura na qual o trânsito entre o passado vivido e o presente em curso vai, de algum modo, influenciar o futuro a viver, e dependendo como os sujeitos dialogam com as suas memórias e também com a dos pares, podem tornar essa releitura mais significativa ou não. Quando a professora Paula diz que aproveitou as dicas dadas por seus pares, reforça não somente a ideia de que os professores reconhecem que a prática de um pode servir de base 
e de modelo para a prática desenvolvida por outro, como também indica a importância da partilha de saberes entre os professores, saberes experiencias, que são defendidos por Tardif (2005) como os que constituem o alicerce da prática e da competência profissionais.

[...] eles sempre pensam sobre o que já viveram e tentam trazer, isso ajuda até a aplicação de novos, novos debates, novas questões, novas atividades mesmo. Isso é algo que os professores fazem sempre de colocar em prática, de socializar sim e trazer pra discussão no momento da nossa reunião as experiências que já passaram, não são todos, mas muitos gostam de falar (OP. Marta - Entrevista).

Almeida (2010) sustenta que permitir que o vivido aflore tem uma forte implicação afetiva, considerada um motor para que novas propostas de trabalho sejam aceitas, e também pode aumentar as possibilidades de releitura da experiência quando confrontada com situações do presente. Desse modo, no momento em que os professores, segundo a orientadora pedagógica Marta, “[...] eles sempre pensam sobre o que já viveram e tentam trazer, isso ajuda até a aplicação de novos, novos debates, novas questões, novas atividades mesmo", fundamenta esta discussão de que é possível, pela memória, fazer transitar o vivido e criar ecos no presente e no futuro. Nesse momento, os envolvidos podem assumir posições diversas, podem ser ora formadores e ora formandos na perspectiva apontada por Nóvoa (1997; 2009).

Eu vejo que tem coisas que os colegas fazem e que a gente precisava de mais tempo pra tá diluindo a informação, tá buscando outras fontes pra poder compreender melhor, mas o tempo é um grande entrave. Então, quem tem possibilidade, às vezes, continua o processo sozinho, eu falo isso até por mim, nem sempre eu consigo né tá retomando... (Professora Adélia - Entrevista)

Essa dinâmica de retomada do vivido nem sempre se traduz como uma dinâmica fácil, pelo contrário, muitas vezes requer dos sujeitos a assunção de que aquele momento de 
rememoração pode potenciar outras experiências mais significativas. Sendo assim, tal empreendimento vai exigir não somente o seu reconhecimento e a sua validação por parte dos indivíduos, mas também, em muitos momentos, que tal processo seja dinamizado por alguém capaz de contribuir para que a interação criada a partir da partilha mais potencializadora desse mesmo processo, que tem implicações no trabalho desenvolvido e a desenvolver, traduza-se em melhoria da qualidade do processo de ensino-aprendizagem.

Alarcão e Canha (2013) apontam que o supervisor, aqui denominado orientador pedagógico, é o profissional capaz de colocar os sujeitos em um movimento de aprendizagem e de interação em que:

[...]interagir com pessoas e criar condições para que elas interajam entre si, interajam consigo e interajam com os ambientes que as cercam, desenvolvendo-se e contribuindo para o desenvolvimento daqueles com que convivem, do campo de atividade em que atuam e dos contextos em que se movem (ALARCÃO; CANHA, 2013, p.76).

A professora Laura fala de um tempo em que a formação acontecia de forma bem diferente da que experiencia hoje, pois não criava espaços para que os professores pudessem atuar mais como intervenientes ativos (LEITE, 2001) de seus processos de trabalho e formação:

[...] hoje a gente vê realmente o professor participando, ele dando a sua opinião, ele trocando experiências, quer dizer você vê uma participação muito maior do professor hoje em dia. Eu mesma participo muito mais, vejo que a gente tem mais abertura pra isso, não precisa só ficar escutando, pelo contrário, acho, né, que existe mais uma vontade da escola pra que a gente se envolva mais, a gente dê nossa opinião, nosso conhecimento, e a gente quer isso. Pra mim, eu acho que assim é melhor, a gente se sente mais importante né. Quando a gente só escutava, acho que os encontros eram chatos, a gente não tinha muita vontade de participar né, agora a gente tem vontade, mas por causa da carga horária nem sempre, né, é possível (Professora Laura - Entrevista). 
Dos dados, pode-se inferir que os professores e orientadoras pedagógicas estão buscando ampliar o foco de visão sobre o próprio trabalho, articulado à formação, no momento em que, lançando mão das suas memórias, criam espaços de reflexão, de avaliação, de aprendizagem e intervenção futura no próprio trabalho. O fato de se colocarem nesse movimento de partilha, em que há uma circulação de saberes, de experiências, de erros, de práticas, de constatações, já os aproxima da perspectiva de Giroux (1997), como intelectuais transformadores capazes de intervir sobre as etapas implicadas no próprio trabalho. Importa salientar que mesmo que os professores ainda não tenham tido a oportunidade de tornar esses momentos de formação como parte integrante da sua atividade docente, devido a inúmeras questões de ordem administrativa, pelas suas próprias condições de trabalho e, até mesmo, pelo reconhecimento e validação atribuídos a esses momentos, pelas alocuções, esses momentos já se constituem significativos para muitos dos envolvidos.

Para Imbernón (2010, p. 65): “A colaboração é um processo que pode ajudar a entender a complexidade do trabalho educativo e dar respostas melhores às situações problemáticas da prática". Nos ateliês, quando a memória torna-se principal conteúdo para se pensar o trabalho desenvolvido e a desenvolver, os professores precisam assumir uma posição colaborativa de modo a potencializarem tal dinâmica de formação. A colaboração ajuda a ampliar as possibilidades de engajamento em um projeto maior de escola, de educação e de trabalho, já que projetos individuais deixam à margem as expectativas e as necessidades de formação e de trabalho do professorado pertencente a uma escola reflexiva (ALARCÃO, 2001) que vai muito além dos limites impostos pelos muros das escolas.

Nesse sentido, trazer a voz dos envolvidos em uma proposta de formação que busca a valorização das próprias experiências por eles vividas como sendo importantes para que possam não só problematizá-las, mas, especialmente, transformá-las em aprendizagens que potencializem o reconhecimento e a abertura de outros caminhos, é fundamental quando se quer a transformação do próprio status quo a partir dos que devem se responsabilizar por 
todas as etapas implicadas em seu trabalho docente.

\section{CONSIDERAÇÕES FINAIS}

A partir do exposto, e tomando por referência a experiência de formação continuada e em serviço que acontecem nos ateliês levados a cabo nas escolas da rede municipal de ensino de Petrópolis - RJ, que tem como uma das matérias-prima da formação a memória, tomada na perspectiva exemplar, em que o uso dessa memória permite utilizar o passado para fins presentes, buscou-se ratificar o potencial da memória nos processos de formação continuada de professores.

Dessa forma, aproveitando as lições das injustiças sofridas para se ficar alerta e encampar uma luta contra as que são produzidas no presente a partir de um enfrentamento mais vigoroso, baseado na experiência que se fortifica no trabalho e na formação implementada colaborativamente. É colocar o passado a serviço do presente, da justiça. Assim, o dever de memória surge não como reparação, compensação de um passado mal vivido, mas abre possibilidades de ressignificação do passado no presente para melhor vivê-lo (TODOROV, 2011a; 2011b).

As alocuções dos professores e orientadoras pedagógicas que trazem, por meio da memória, situações vividas e reflexões sobre seus processos de trabalho e de formação surgem como expressivo material para se pensar na importância de projetos, propostas de formação que promovam um mergulho no passado vivido para poder se pensar, prospectivamente, no futuro.

A memória será importante aliada nesse processo de formação continuada e em serviço de professores uma vez que ajudará os professores a construírem, coletivamente, a sua história passada de formação e de trabalho para, a partir dela e com ela, buscarem subsídios para viverem bem e com justiça, no que se refere às condições de trabalho e de valorização, a sua profissão docente. Nesse sentido, resgatar o passado é também problematizar o presente e qualificá-lo.

Diante disso, considero imprescidível trazer para a mesa de discussões sobre a formação e o 
trabalho dos professores não apenas estudos e concepções de pesquisadores renomados, mas, especialmente, nesse diálogo, trazer a voz de professores e orientadoras pedagógicas que estão vivendo uma experiência de formação continuada centrada na própria escola, que, embora se encontre em pleno processo de construção, reconhecimento e validação pelos envolvidos, já se revela significativa para muitos deles. Assim, defende-se que a formação continuada de professores é um

[...] processo complexo que envolve a apropriação de conhecimentos e saberes sobre a docência, necessários ao exercício profissional, em que se toma a escola como lócus privilegiado para a formação. Parte-se do pressuposto do professor como sujeito capaz de criar e recriar sua própria formação, assumindo-se como protagonista desse processo. Entende-se que a formação é um processo em que o professor vivencia de forma deliberada e consciente a construção de sua autonomia e autoria profissional, em um movimento de ser, pensar e fazer a docência (BENACHIO; PLACCO, 2012, p. 58).

Quando os professores e as orientadoras pedagógicas percebem que a memória dos sujeitos, quando considerada exemplar, ajuda a pensar os projetos, o trabalho, a própria formação continuada de modo a tornar os professores mais envolvidos em seus próprios processos de formação e trabalho com vistas a melhorar e qualificar a sua docência.

Nóvoa (2009) chama a atenção para o fato de a formação não ser construída a partir da acumulação de cursos, de conhecimentos e de técnicas, mas, sim, por meio de um trabalho de reflexividade crítica sobre as práticas e de (re) construção permanente de uma identidade pessoal, pois a pessoa do professor deve ser sempre valorizada e o saber, vindo da sua experiência, deve ser legitimado. A partir do exposto, retomasse o potencial da memória para tornar os espaços de formação continuada mais significativos para articulação trabalhoformação e formação-trabalho.

Muitos professores ainda não consideram, ou pior, desqualificam sua trajetória de formação e de trabalho quando se deparam com situações em seu cotidiano que poderiam ser 
apreciadas a partir de tudo o que eles já viveram, podendo no tempo presente, retirar algum ensinamento. O que Todorov (2011a; 2011b) chama de memória exemplar é, justamente, o potencial de aprendizagem que um acontecimento passado pode ter no presente, quando rememorado com consciência e comprometimento, buscando vestígios que possam consolidar momentos presentes mais adequados e mais bem vividos.

Se os professores pudessem olhar para o seu passado não como uma história morta, mas como uma história vivida com potencial para se viver melhor o presente, retirando do passado várias aprendizagens, quanto se poderia avançar, tornando a atividade docente mais significativa para professores e alunos?

A ênfase atribuída a uma memória pretérita não se define na crença, ou assunção, de que a escola precise viver de seu passado, mas há muitos eventos e histórias que merecem ser rememorados para que a trajetória que se realiza no presente seja enriquecida por experiências vivenciadas em uma longa caminhada anterior, que sirva como referência, como um marco inicial. A consideração do tempo já transcorrido e a transcorrer na escola é muito importante para a escolha dos caminhos que se quer percorrer e o alcance dos objetivos traçados.

Desse modo, quando a memória surge no processo de formação continuada e em serviço de professores como exemplar, com seus bons usos (TODOROV, 2011a; 2011b) pode abrir caminhos para que esses sujeitos possam ressignificar a trajetória vivida e buscar outros caminhos, experiências, saberes, conhecimentos para fundamentar e orientar o que ainda vão experienciar na sua docência a partir de uma perspectiva que privilegia todas as experiências narradas uma vez que nada pode ser perdido para a história (BENJAMIN, 1996). Sendo assim, importa dizer que para tratar de questões relacionadas à formação de professores, seja essa inicial ou continuada, centrada na escola ou fora dela, pensada, elaborada e dinamizada por sujeitos externos à escola ou pelos próprios professores e orientadores pedagógicos a partir de seu próprio trabalho como conteúdo de formação, 
deve-se exigir a participação dos professores como principais protagonistas, capazes de tomar decisões sobre como, onde e por que precisam, no exercício de sua atividade docente, como sujeitos inacabados, lançarem-se permanentemente em um processo de aprendizagem, sem desprezar o já vivido.

Nessa perspectiva, considera-se imprescidível trazer para a mesa de discussões não apenas estudos e concepções de pesquisadores renomados sobre essa temática, mas, especialmente, nesse diálogo, trazer a voz de professores e orientadoras pedagógicas que estão vivendo uma experiência de formação continuada centrada na própria escola, que, embora se encontre em pleno processo de construção, reconhecimento e validação pelos envolvidos, já se revela significativa quando retoma o vivido como memória exemplar.

\section{REFERÊNCIAS}

(espaçamento simples, com 0,20 cm depois do parágrafo)

ALARCÃO, Isabel. Formação continuada como instrumento de profissionalização docente. Em: VEIGA, IIma Passos Alencastro (Org.). Caminhos da profissionalização do magistério. Campinas, SP: Papirus, 1998, p. 99-122 - Coleção Magistério: Formação e trabalho pedagógico.

. Escola reflexiva e supervisão. Uma escola em desenvolvimento e aprendizagem. Em:___(Org.). Escola reflexiva e supervisão. Uma escola em desenvolvimento e aprendizagem. Porto, Portugal: Porto Editora, 2001, p.11-23 - Coleção Cidine.

Professores reflexivos em uma escola reflexiva. 7. ed. São Paulo: Cortez, v. 8, 2010a - Coleção questões de nossa época.

; CANHA, Bernardo. Supervisão e colaboração: uma relação para o desenvolvimento. Porto, Portugal: Porto Editora, 2013.

ALMEIDA, Laurinda Ramalho de. A coordenação pedagógica no estado de São Paulo nas memórias dos que participam de sua história. Em: ; PLACCO, Vera Maria Nigro de Souza (Orgs.). 0 coordenador pedagógico e o atendimento à diversidade. São Paulo, SP: Edições Loyola, 2010, p. 11-45.

BARDIN, Laurence. Análise de conteúdo. Lisboa: Edições 70, 2013.

BENACHIO, Marly das Neves; PLACCO, Vera Maria Nigro de Souza. Desafios para a prática da 
formação continuada em serviço. Em: ALMEIDA, Laurinda Ramalho de; PLACCO, Vera Maria Nigro de Souza. $\mathbf{O}$ coordenador pedagógico: provocações e possibilidades de atuação. São Paulo: Edições Loyola, 2012, p. 57-70.

BENJAMIN, Walter. Obras escolhidas: magia e técnica, arte e política. Tradução de Sérgio Paulo Rouanet. São Paulo: Brasiliense, 1996.

BOGDAN, Robert; BIKLEN, Sari. Investigação Qualitativa em Educação: uma introdução à teoria e aos métodos. Porto, Portugal: Porto Editora, 2010.

COSTA, António Pedro. LINHARES, Ronaldo; NERI DE SOUZA, Francislê. Possibilidades de Análise Qualitativa no WebQDA e Colaboração entre Pesquisadores em Educação em Comunicação. Em: SIMPÓSIO DE EDUCAÇÃO E COMUNICAÇÃO, 3., 2012, Aracaju. Anais, 2012, p. 276-286, ISSN 2179-4901.

FORMOSINHO, João. Formação de Professores: aprendizagem profissional e acção docente. Porto, Portugal: Porto Editora, 2009.

FREIRE, Paulo. Pedagogia da Autonomia. Saberes necessários à prática educativa. 31 ed. Rio de Janeiro: Paz e Terra, 2005.

GIROUX, Henry A. Os professores como intelectuais: rumo a uma pedagogia crítica da aprendizagem. Porto Alegre: Artes Médicas, 1997.

IMBERNÓN, Francisco. Formação permanente do professorado: novas tendências. São Paulo: Cortez, 2009.

Formação continuada de professores. Tradução de Juliana dos Santos Padilha. Porto Alegre: Artmed, 2010.

. Formação docente e profissional: formar-se para a mudança e a incerteza. Tradução de Luciana Cobucci Leite. Coleção Questões de nossa época, v. 14, 9. ed. São Paulo: Cortez, 2011.

LEITE, Carlinda. Lugar da escola e do currículo na construção de uma educação intercultural. Em: Canen, A; Moreira, A. F. B. (Orgs.). Ênfases e omissões no currículo. São Paulo: Papirus, 2001.

MACHADO, Jane do Carmo. O potencial da memória exemplar para a formação continuada e em serviço de professores. Trabalho de conclusão de estudos de Teoria da Educação do Curso de Doutorado em Educação da Universidade Federal Fluminense. Niterói, RJ: PPGEUFF, 2011.

Ateliê de formação continuada e em serviço de professores: desafios e possibilidades. 2015. 272f. Tese (Curso de Doutorado em Educação) - Faculdade de Educação. Universidade Federal Fluminense, Niterói, RJ, 2015. 
NÓVOA, António (Org.). Os professores e sua formação. Lisboa: Publicações Dom Quixote, 1997.

.Para uma formação de professores construída dentro da profissão. Revista Educación, 2009. Disponível em: <www.revistaeducacion.mec.es/re350/re350_09por.pdf>. Acesso em: 21 fev. 2014.

SARMENTO, Teresa. Contextos de vida e aprendizagem da profissão. Em: FORMOSINHO, João. Formação de Professores: Aprendizagem profissional e acção docente. Porto, Portugal: Porto Editora, 2009, p. 303-327.

TARDIF, Maurice. Os saberes docentes e formação profissional. 5 ed. Petrópolis, RJ: Vozes, 2005.

VELHO, Gilberto. Observando o Familiar. Disponível em: <navi.paginas.ufsc.br/files/2012/03/VELHO-Observando-o-Familiar.pdf>. Acesso em: 20 maio 2012. 